Article

\title{
Future Outlook of Highway Operations with Implementation of Innovative Technologies Like AV, CV, IoT and Big Data
}

\author{
Muhammad Azmat $^{1, *(D)}$, Sebastian Kummer ${ }^{1}$, Lara Trigueiro Moura ${ }^{2}$, Federico Di Gennaro ${ }^{3}$ \\ and Rene Moser 4 \\ 1 Institute for Transport and Logistics Management, WU (Vienna University of Economics and Business), \\ Welthandelsplatz 1, 1020 Vienna, Austria; sebastian.kummer@wu.ac.at \\ 2 A-to-Be (Brisa), Lagoas Park, Ed. 15, Piso 4, 2740-267 Porto Salvo, Portugal; lara.moura@a-to-be.com \\ 3 AISCAT Servizi, Via Gaetano Donizetti, 10, 00198 Roma, Italy; federico.digennaro@aiscatservizi.com \\ 4 ASFINAG, Rotenturmstraße 5-9, 1010 Vienna, Austria; rene.moser@asfinag.at \\ * Correspondence: mazmat@wu.ac.at
}

Received: 28 April 2019; Accepted: 14 June 2019; Published: 19 June 2019

\begin{abstract}
In the last couple of decades, there has been an unparalleled growth in number of people who can afford motorized vehicles. This is increasing the number of vehicles on roads at an alarming rate and existing infrastructure and conventional methods of traffic management are becoming inefficient both on highways and in urban areas. It is very important that our highways are up and running $24 / 7$ as they not only provide a passage for human beings to move from one place to another, but also are the most important mode for intercity or international transfer of goods. There is an utter need of adapting the new world order, where daily processes are driven with the help of innovative technologies. It is highly likely that technological advancements like autonomous or connected vehicles, big data and the Internet of things can provide highway operators with a solution that might resolve unforeseeable challenges. This investigative exploratory research identifies and highlights the impact of new technological advancements in the automotive industry on highways and highway operators. The data for this research was collected on a Likert scale type online survey, from different organizations around the world (actively or passively involved in highway operations). The data was further tested for its empirical significance with non-parametric binomial and Wilcoxon signed rank tests, supported by a descriptive analysis. The results of this study are in line with theoretical and conceptual work done by several independent corporations and academic researchers. It is evident form the opinions of seasoned professionals that these technological advancements withhold the potential to resolve all potential challenges and revolutionize highway operations.
\end{abstract}

Keywords: autonomous vehicles; connected vehicles; internet of things; Big Data; highway; highway operations; innovation in mobility; transportation; self-driving cars

\section{Introduction}

This study was commissioned to examine the impact of the influx of innovative technologies on highway operators, toll operators and on the highway itself. The performance of highways and the organizations involved in highway operations is very crucial in measuring the economic health of any country. The better the throughput of the highways, the better would be the results driven from it. This is the responsibility of highway operators to make sure that the highway is up and running 24/7-365. In this modern, technologically advanced era, it is very important to keep up with the pace of innovation to ensure that highways and their operating systems are up to date and qualify for modern 
world requirements. This study will also allow highway operators to assess the future needs and tweak or modernize their existing systems to make them fit to meet the requirements of tomorrow.

A constant evolution of transportation systems and new technologies is essential for better societies and economies [1]. The advent of new technologies like, self-driving cars, connected vehicles, Internet of things, big data and smart logistics, have a big potential to change the outlook of almost everything including how we commute daily to how goods are being delivered or transported from one place to another. Over a short period, innovation in automobile and information technology has seen an unprecedented growth, and this study draws attention towards these innovations having a greater impact on highway or toll operators. An ever-increasing need for freight and public transport has been seen all over the world. This need calls for efficient road transport, which is highly flexible in terms of distance covered by people and nature/number of goods transported. However, it also puts a lot of strain on the difficult-to-expand bottlenecks and existing infrastructures. Increasing urbanization causing an upsurge in urban population, as well the needs of the population, will shape the future of transport [2]. Recently, the advancement in technology has influenced the automobile industry largely, by introducing automated driving, which is a new concept to many [3]. Conventionally, people have always driven vehicles, however, new technology offers automation in driving by the use of communication, controls and embedded systems [4]. Over the next few years, there will be a paradigm shift in road transportation, with the release of autonomous vehicles on the road connected with [5] the Internet of things [6] and big data [7]. These technological advancements will make highway commuting easier and more efficient, however, they may also pose some difficult challenges [7]. While ingenious, modern communication technologies provide an intensive tracking and monitoring system for vehicles and infrastructure, and in keeping with the safety and security legislative framework, they also require effective policies and infrastructure to handle the flow of automated traffic. In order to prepare them for facing the challenges of the future, and to equip them for the opportunities that it holds, it is essential that our highway operators should be aware of these technological advancements.

There has been an unprecedented growth in population of those who can afford motorized vehicles (especially cars) and society's demand for mobility has increased exponentially over the past decades. These factors indicate that in the future, the number of road participants is likely to increase [8]. Moreover, many of the existing roads and highways have reached their limitations-main traffic routes are constantly congested. Furthermore, it has been often suggested that neither is there room for geographical expansion especially of arterial roads, nor are conventional traffic management systems capable of solving these great challenges of traffic management [9]. Thus far, scientific work by research has highlighted mainly the technical aspects, potential societal and policy impacts of modern technological advancements in the automotive industry, for example, as discussed by [3,9-12] and many others. However, to the best of the authors knowledge, their impact on highway or toll operators has mostly been neglected and very little work has been examined in this direction $[7,10,11]$. This study is the starting point for understanding and exploring the organizations' point of view on how innovative technologies would affect highway operators, toll agencies and highways in the future [12]. More precisely, this study tries to find the answers to the following questions:

1. What is the expected maturity time line of innovative technologies (internet of things, big data, and autonomous vehicles) for highway applications and how would they affect the business paradigm for highway operators?

2. What is the expected percentage of autonomous vehicles on highways until 2030?

3. What would be the impact of innovative technologies (big data, Internet of things, connected vehicles and autonomous vehicles) on highways and highway operators?

4. Which potential areas require critical initial investments to facilitate autonomous vehicles on highways?

The purpose of this research is to identify the time it would take for above mentioned technologies to be ready for implementation by highway operators. It is important, as it would facilitate the policy 
makers for such organizations in long term organizational planning, redefining and reshaping the existing code of conduct. Furthermore, it tries to identify their potential benefits, allowing highway operators to plan for and avail all the opportunities that come with technological advancements. Moreover, this study attempts at making highway operators aware of the challenges they might face in the future.

\section{Literature Review}

Human beings first started driving cars approximately a hundred years ago [13]. Since the first cars were made and driven, a remarkable but steady development has been observed in the automotive industry. However, recently an exponential technological growth has been observed in this industry. In this section, the authors will highlight the current state of modern technologies, as well as potential benefits and challenges so far discussed by different research.

\subsection{Autonomous Vehicles (AV)}

An autonomous or self-driving vehicle is one that can drive itself from one point to another given point, without active control and input from a human driver [14]. However, every commercial automobile manufacturer has its own definition of an autonomous vehicle [11]. The National Highway Transportation Safety Administration (NHTSA) [15] defines an autonomous vehicle to be a vehicle which falls under category 4 or 5 on their automation chart as shown in Figure 1. Autonomous vehicles are expected to be fully self-sufficient in any given environment and that makes them different from connected vehicles, as they mostly rely on a greater degree of coordination among vehicle manufacturers and traffic regulation authorities [1].
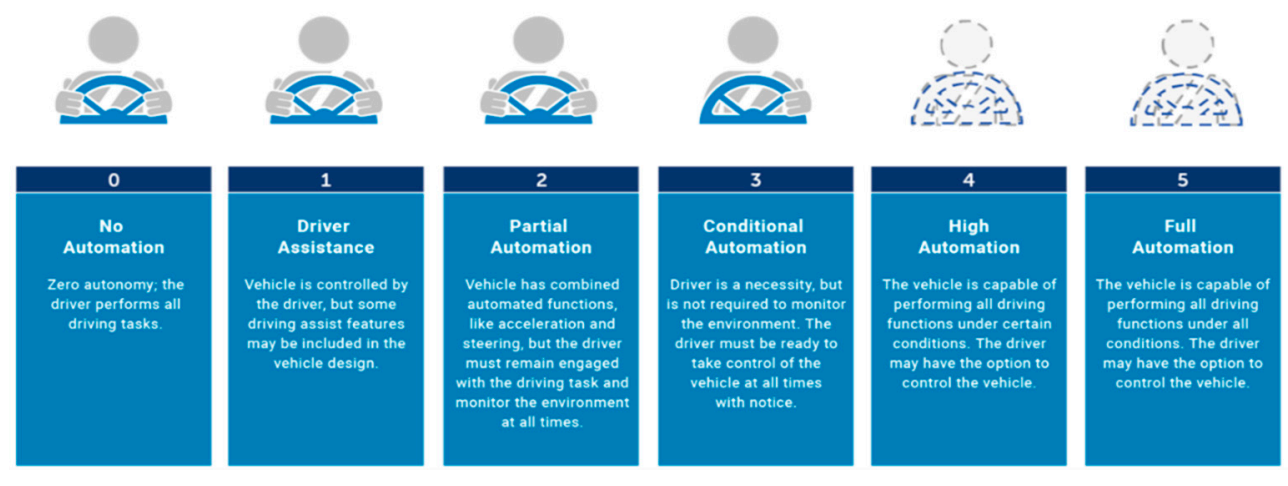

Figure 1. Levels of vehicle automation by NHTSA $[15,16]$.

\subsubsection{General Description}

Autonomous driving is considered to be the biggest transformative development in the post-modern era, which will change the dynamics of transportation. As it is based on the use of inventive and modern technology, its impacts on road transport are diverse [17]. These include enhanced vehicle and road safety, reduced impedance of traffic and a change in travel behavior [3].

\subsubsection{Expected Benefits and Challenges of AV}

The potential benefits AVs can provide largely depend on the level of automation [18]. As machine learning technologies are getting more and more reliable, it is helping to create an absolute artificial intelligence system. That is, a system which is not only capable of making decisions, but right decisions on right time. This technology when applied to cars create remarkable road vehicles which are capable of using these machine learning algorithms to drive themselves from one point to other, solving multi-level challenges and making several spontaneous right decisions [19]. According to Litman [20] and Kyriakidis et al. [21], it is predicted that autonomous vehicles will escalate convenience and safety of travelers, reduce hindrance caused by congestion and limit fuel consumption. Further, Mahmassani [1] 
highlights that AVs have a potential to significantly reduce costs of dynamically scheduled services and individual car ownerships, as more and more people drift towards using the shared cars model for commuting or travelling. It would also eliminate the performance limitations of the human driver. Moreover, Fagnant and Kockelman [3] proposed that AV operations are inherently different from human-driven vehicles. AVs will be configured to follow traffic laws, have lesser reaction time, control the flow of traffic, improve fuel economy and reduce emissions. Autonomous vehicles can even be made to gauge the breaking and acceleration decisions of surrounding vehicles to avoid congestion and drastically reduce road accidents. Several studies conclude that a pivotal impact of autonomous vehicles would be reduced congestion, increased road safety and an increased highway capacity as discussed by Bierstedt et al. [11], Milakis et al. [22] and Gkartzonikas \& Gkritza [23]. Milakis et al. [21] further added that road capacity could be enhanced by AVs improving driving behavior relating to time gaps, speed and lane changes. Another weighty benefit AVs can provide is the much-needed mobility solution for the elderly and disabled people, which is also note-worthy [3].

An autonomous vehicle may easily administer common road situations. However, to design a system that can perform safely in every situation is a very challenging task. Some research also concludes that autonomous vehicles can be an easy target for cyber-crimes, vandalism and passenger security issues that might also arise as shared mobility comes into play and several studies agree that AVs would be very difficult to regulate $[3,14,20,23,24]$. Apart from technological maturity and reliability, concerns about liability and insurance challenges in case of failure of onboard systems or an accident, are some of the biggest hindrances in the diffusion of AVs with existing laws and regulations. There is an ongoing debate regarding who should be held responsible in case of an accident-the owner or the user of the AV $[14,23,24]$.

\subsection{Connected Vehicles (CV)}

According to Cheng et al. [25], connectivity supported and enabled vehicles that can correspond with their internal and external surroundings are referred as connected vehicles. These vehicles wirelessly perform certain activities, i.e., supporting the communications of the vehicle to the sensor on board (V2S), vehicle to infrastructure (V2I), vehicle to vehicle (V2V) and vehicle to everything (V2X). The CV technology intends to provide a platform to create an interconnected network between vehicles in motion and stationary infrastructure, which will enable vehicle and individuals to communicate with one another [1]. The concept of these technologies has been in development in the U.S. and Europe for decades, with the initial goal of providing a range of potential benefits, such as traffic safety and efficiency [26].

\subsubsection{General Description}

Past achievements in the automotive industry focused on protecting the driver in case of an accident. Safety systems such as the airbag, seat belts and later on, anti-lock braking system (ABS) and electronic stability control (ESC) were introduced in cars for driver safety and protection [27]. However, recent developments show that the focus has shifted towards accident prevention: "Whereas most developments in transportation safety over the past 50 years were designed to protect passengers in the event of a crash, V2I [vehicle to infrastructure] and V2V [vehicle to vehicle] systems are being designed to help motorists avoid the accident altogether." [28]. There are numerous projects that contribute to inter-vehicle communication (IVC) research and development [29].

In above mentioned communication technologies which make an automobile connected, V2I and $\mathrm{V} 2 \mathrm{~V}$ are among most advanced ones in today's world. V2I means that the transport infrastructure sends valuable information to vehicles regarding traffic and road conditions, collision danger, speed limitations, traffic jams at intersections, etc. and recommends certain actions to vehicles situated in traffic. The communication between two or more vehicles, V2V, aims at the interaction and collaboration between them. The information that is interchanged is based on the on-site traffic aspects. Vehicles located within a certain distance form a network, communicate with each other, and together, make 
decisions to enable better traffic management [30]. Further, Knapik et al. [31] also expresses that communication between vehicles and mobile devices is becoming progressively important for our lives. Moreover, intelligent transport systems (ITS) classify V2X into road safety, traffic management, infotainment V2X services, and autonomous driving platforms. Road safety applications help mitigate road accidents and lower driving fatality numbers by detecting mobile fixed obstacles and avoiding collisions, and by using emergency electronic brake lights. It also provides weather information and accident notifications [32].

\subsubsection{Expected Benefits and Challenges of CV}

Connected vehicles are practical, up-to-date and synchronized. For instance, according to Noori \& Valkama [33], V2X communication has a potential to improve traffic efficiency, road safety, and the availability of infotainment services. Wireless communication technology has been developed in order to make vehicles capable of communicating with road side units (RSU) and with one another in order to solve traffic-related problems, by monitoring traffic in real-time and identifying the best route for the drivers. This can reduce high traffic volumes, numbers of accidents especially in urban areas, and can help drivers find the best route by providing them with on-line traffic data. Such technological advancements would also assist with several applications for road safety (like, lane change warning, collision detection or prevention and cooperative merging), green and smart transportation (for example; intelligent traffic signal controlling and scheduling, better fleet management, etc.). CVs would also offer location dependent services (like, POI and route optimization, etc.) and access to the internet in-vehicle [25].

Furthermore, reliable V2V communication is a key technology to realize the advanced intelligent transport system (AITS) that supports safe driving and enhances automated driving systems [34]. For V2V technology to work seamlessly, each vehicle is assumed to be equipped with an on-board unit (OBU), GPS receiver, a DSRC radio, and enough computing power to track other vehicles [35]. The OBU is responsible for storing the real identity of the vehicle and synchronizing the diversified information [36]. Any helpful information collected from sensors on a vehicle may be sent to neighboring vehicles [37].

It is unquestionable that the number of vehicles on the roads is permanently increasing, especially in urban areas. Since traffic congestions have mostly negative consequences, such as increasing travel time, fuel consumption, and air pollution, vehicle-to-infrastructure (V2I) communication has been developed to mitigate all these problems [38]. V2I communication is able to estimate the traffic density in a certain areas, which represents a key parameter to perform efficient traffic redirection, thereby reducing travel time [39]. Moreover, Dixit et al. [40] suggests, a connected network of vehicles and its surroundings enable V2I communication to keep track of the vehicular environment and disburse real-time traffic, road conditions, vehicle density and weather updates, thus improving the overall traffic situation.

However, every technology comes at certain cost and so do connected vehicles. While research on connected vehicle networks has progressed remarkably, there are still significant obstacles presented by connected vehicle networks. One such issue is the spectrum scarcity problem [41]. High vehicle speed and high user density, especially in an urban environment, lead to high carrier frequency which leads to frequency error, inter-carrier interference and insufficient channel estimation due to shorter coherence time [42]. The issue of spectrum shortage in wireless communication, the spectrum scarcity and channel overcrowding will apparently pose a difficulty for existing and upcoming vehicular applications [43].

There are numerous other threats highlighted by researchers in the field and one such critical threat is cyber-crime. The communication between devices is achieved with the help of sensors, tags and radio frequency identification (RFID), that put in danger data authentication and integrity. This kind of wireless communication is still vulnerable to cyber-attacks. Improving the security of the IoT technology should be one of the priorities in the further development of this network, as only by 
achieving top security of data, IoT could be used at its full potential [44]. According to Zhang et al. [45], one form of cyber threat is malware-malevolent software designed to disrupt computerized actions or gain illegal and unlawful access to information. Malware can corrupt vehicles through numerous entry points such as Wi-Fi hotspots on vehicles, wireless communication with roadside networks, internet connectivity, infected consumer electronic devices (for example, memory storage devices, USB, smart phones etc.) connected wirelessly or physically to the vehicle. The known weaknesses in the design and application of on-board communication systems, software, hardware, and applications, can be subjugated by malware to infect a vehicle.

\subsection{Internet of Things (IOT)}

Since first introduced by Kevin Ashton in 1999 the term, Internet of things, has been redefined and used by several scholars. IoT describes the movement that increasingly more tangible things are connected to the Internet. Each device has a unique identification number (UID) and an Internet protocol (IP) and connects via wires, cellular networks, Wi-Fi or Bluetooth [45]. The IoT basically consists of connected tangible things that normally exchange digital data with one another [46].

\subsubsection{General Description}

According to Press [46], Forbes estimates that approximately $87 \%$ of all people until 2014 had never heard of the term Internet of things, although, it is not a new concept and has its roots in the late 1990s. Many inventions and advancements made IoT possible as we know it today, these technologies include but are not limited to: Barcodes, scanners, radio frequency identification (RFID) tags and receivers, the Advances Research Project Agency Network (ARPAnet), then the Internet, etc. Connected cars also fall in this category, as they are capable of exchanging data with other vehicles, infrastructure elements and other devices. The problems currently faced by highways, freeways and urban areas can be addressed using technology-based solutions like the Internet of things and big data. These technologies mainly involve the Internet and GPS (global positioning system) enabled devices, to provide valuable information from several data points, in combination with cameras, sensors, radio frequencies and other tools using similar technologies [47-49].

Over two billion people around the world use the Internet for daily tasks, from sending and receiving emails to controlling house appliances. As more and more people join the network of global information and communication infrastructure, another big leap forward is coming, connected to the use of the Internet as a universal podium for letting machines and smart objects interconnect, dialogue, calculate and coordinate [6]. This idea of physical objects being connected to the Internet at an unparalleled rate brings society one-step closer to the realization of the idea of the Internet of things (IoT). This technology will transform traditional objects into smart objects by exploiting its underlying technologies, such as, permeating and persistent computing, communication, sensor networks and Internet protocols [50]. IoT has incredible potential of transforming the future, where almost every consumer device, from cars to a coffee mug, may connect through the Internet. This will lay the foundation of data points, which would lead to a better society by providing enormous quantities of valuable sensory data for analytics and other uses [51].

\subsubsection{Expected Benefits and Challenges IOT}

In case of highways and urban areas, IOT would bring with it several benefits, for example; using cars as smart objects, it will be possible to avoid congestion by monitoring traffic in real time and deploy services that offer traffic routing advice for better traffic management. In addition, parking issues in urban areas can also be mitigated by using smart parking devices systems, based on RFID and sensor technologies that will observe available parking spaces and provide drivers with automated parking advice in real time resulting in improvement of mobility in urban area. Moreover, internet connected sensors may also monitor the flow of automobiles on highways and gather useful information such as numbers of cars at any given point in time and place and their average speed. IOT enabled tools on 
highways could detect level of carbon dioxide, PM10, etc. and distribute such information to health agencies. Furthermore, connected sensors and other devices could be used in some highway settings for detection of traffic and speed violations and transmit the related data to law enforcement agencies for recognizing the violator or to save details for following accident scene investigation [6].

As the world becomes more interconnected through the Internet it gives birth to an interesting digital phenomenon in technology world known as the Internet of things (loT), but this technology brings with it many legal challenges. These challenges may include, but are not limited to, privacy desecrations and security risks [51]. According to Miorandi et al. [6] and Bandyopadhyay \& Sen [52], security is a critical aspect of the widespread adoption of IoT technologies and applications. Stakeholders are unlikely to adopt IoT solutions on a large scale unless system level confidentiality, authenticity and privacy are guaranteed. They further added data confidentiality which signifies an essential issue in IoT setups and that only ratified bodies should be able to access and alter data. The discussion also includes that privacy and trust are very important factors when addressing IoT applications and rules must be demarcated under which, data concerning individual users may be retrieved [51]. Further, privacy issues are addressed as the legal community is required to prepare for this stirring yet alarming digital era and the privacy challenges that will escort its arrival.

\subsection{Big Data}

"Data's true value is like an iceberg floating in the ocean", as information technology matures, it is reducing the cost of collecting data and this allows individual and organizational data generation and recording extremely effective and efficient [53]. The fact that increasingly more tangible things are connected to the Internet, and more and more people use computers, the amount of data generated is rising at a record rate [46]. However, the data collected alone does not create any value, it needs to be processed, bundled, sorted, etc. to create valuable information which is referred as big data.

\subsubsection{General Description}

Big Data can revolutionize how people drive. More data, if processed, can lead to more information [54]. As cars today collect the driving and other types of data from their surroundings and other cars and by analyzing and processing this data, car manufacturers and original equipment manufacturers create economic value [48]. Some of the key examples of big data applications in the car are: Inrix, an application that provides traffic information and navigation; GM's OnStar, where a digital crash signature is collected in case of an accident; Tesla's over the air software updates $[55,56]$.

As one of the fundamental human needs, transportation also confronts the promises and challenges brought about by the big data era. Big data in the transportation arena is enabled by the rapid popularization of the intelligent transportation system (ITS) which has combined various technologies of the information era such as communication technologies, computers, sensors, the Internet, etc., in order to solve road traffic issues on a large scale [28,57]. In the past few decades, the information is often collected continuously from different sources over vast geographic scales. While being huge in size and rich in information, the seemingly disorganized data could considerably enhance an experts' understanding of their system [7]. In addition, global positioning systems and other advanced communication technologies have made it possible to collect real-time traffic data from a wide range of heterogeneous sensor sources. This allows advanced traffic state estimations and predictions for important transportation management applications [49]. With the shrinking costs and increased accuracy of GPS, cellphone-based traffic monitoring makes extensive spatial and temporal coverage more accessible than the use of traffic sensors. Mobile phones are also considered the best means of data collection and transmission. The penetration rate for such smart phones is over $50 \%$ in the developing world and between 90 to $100 \%$ in developed countries [58].

The methods of traffic data collection have been classified in following four categories as explained by Dong et al. [49]: 
- Sensor-based traffic information collection technologies, such as inductive loop detectors, microwave radar, laser radar, magnetometers, and ultrasonic detectors.

- Video-based traffic information collection technologies, such as license plate recognition (LPR) systems.

- Radio-frequency-based traffic information collection technologies, such as radio frequency identification (RFID) and dedicated short-range communications (DSRC).

- Location-based traffic information collection technologies, such as GPS-equipped floating cars. In the automotive industry, the general purpose of these sensors, smartphones and embedded technologies is to facilitate traffic management and avoid certain obstacles.

\subsubsection{Expected Benefits and Challenges of Big Data}

GPS-enabled, cellular phone-based traffic monitoring systems would enable highway operators to assess the traffic situation on highways more precisely than ever before, with real time information on the flow of traffic and identification of congestion and predicting possible mishaps [7,58,59]. Furthermore, Hossain \& Muromachi [60] and Pande \& Abdel-Aty [61] added that data gathered from sensor and video surveillance could assist in predicting real time crashes, making expressways more secure.

Despite this, potential benefits of big data are real and significant, but there remain some technical problems. These technological challenges include but are not limited to heterogeneity of data collected by embedded sensors and other data resources. For machines, it is already difficult to analyze and manipulate homogeneous data and the data gathered from the big data resources are usually heterogeneous, inconsistent and incomplete making it even more difficult for machines to work with it [62]. Other prominent concerns discussed by studies [58,62] are privacy and data ownership. Sharing information to track a person on the move can compromise privacy, hence there is a fear of inappropriate use of personal data.

\subsection{Summary of Expected Key-Benefits and Challenges of Innovative Technologies}

Table 1 below summarizes the key benefits and challenges of all innovative technologies discussed in the literature above. Moreover, it also mentions, which authors or papers contributed to enlist these benefits and challenges.

Table 1. Key-benefits and challenges of innovative technologies.

\begin{tabular}{|c|c|c|c|}
\hline Technology & Key-Benefits & Key-Challenges & References \\
\hline Autonomous Vehicles & $\begin{array}{l}\text { Increased convenience and safety of } \\
\text { travelers, improved flow of traffic, } \\
\text { highway capacity, fuel economy, better } \\
\text { mobility for elderly and disabled } \\
\text { people and reduced costs, congestion, } \\
\text { emissions and road accidents }\end{array}$ & $\begin{array}{l}\text { Possible threat of } \\
\text { cyber-crimes, cyber security } \\
\text { and difficulties in laws, } \\
\text { regulations and insurance } \\
\text { debates }\end{array}$ & {$[1,3,11,14,18-21]$} \\
\hline Connected Vehicles & $\begin{array}{l}\text { Improved traffic efficiency, road safety, } \\
\text { infotainment services, communication } \\
\text { with road side units, location } \\
\text { dependent services, v2v and v2i } \\
\text { communication, enhances automated } \\
\text { driving, reduction in travel time, real } \\
\text { time decision making, }\end{array}$ & $\begin{array}{l}\text { Spectrum scarcity problem, } \\
\text { computational errors, high } \\
\text { user density might lead to } \\
\text { frequency errors, } \\
\text { cyber-crime, cyber security } \\
\text { threat }\end{array}$ & {$[23,31-35,37-43]$} \\
\hline Internet of Things & $\begin{array}{l}\text { Help avoid congestion, real-time } \\
\text { traffic management, smart parking } \\
\text { solutions, improved flow of } \\
\text { automobiles on highways, detection of } \\
\text { traffic and speed violations, } \\
\text { environment monitoring }\end{array}$ & $\begin{array}{l}\text { Privacy desecrations and } \\
\text { security risks, data } \\
\text { confidentiality concerns }\end{array}$ & {$[6,45-47,49,50]$} \\
\hline Big Data & $\begin{array}{l}\text { Better traffic monitoring systems, } \\
\text { avoiding congestion, accidents } \\
\text { prevention, real time monitoring }\end{array}$ & $\begin{array}{l}\text { Heterogeneous data difficult } \\
\text { to process, data privacy, } \\
\text { data ownership and usage } \\
\text { concerns }\end{array}$ & {$[7,56-60]$} \\
\hline
\end{tabular}




\section{Methodology}

This is an exploratory study, where primary data was collected from organizations across the world actively or passively involved in highway operations be it in the form of consultation, support or supplies, etc. The main purpose of this study is to understand and evaluate the potential impact of innovative technologies on highways and highway operators.

\subsection{Data Collection}

As discussed by Meek et al. [63], a Likert scale style survey tool was selected for this study, where respondents were asked for their views and opinions on innovative technologies (more precisely about autonomous, connected vehicles, the Internet of things and big data) and their impact on highway operators. The scale measures from 1 to 5 with one being strongest response and 5 being weakest response.

The survey was executed using a lime survey, an online tool to conduct surveys. The tool assigned a system which generated an ID for each respondent in order to keep the data unbiased and anonymous. The type of data mainly collected through this survey was ordinal data.

\subsection{Respondents}

The survey was distributed to nearly 200 different members of the International bridges tunnels and turnpike association (IBTTA). At the end of the survey, the authors received 83 responses in total, however, 51 of them were completed and rest were incomplete, therefore, they were not considered fit for analysis and discarded. Therefore, 51 respondents made approximately $25.5 \%$ of the total target population. The breakup of participating organizations can be seen in Table 2.

Table 2. Breakup of participating organizations.

\begin{tabular}{ccc}
\hline Organization Type & Frequency & \% \\
\hline Association & 02 & 3.90 \\
Other & 05 & 9.80 \\
Supplier & 08 & 15.7 \\
Consultant & 12 & 23.5 \\
Highway operator/Toll agency & 24 & 47.1 \\
\hline Total & 51 & 100 \\
\hline
\end{tabular}

\subsection{Research Technique}

After the initial assessment of the data, it was observed that the data does not meet the assumption of approximate normal distribution. Therefore, a nonparametric statistical testing approach was adopted [63]. The research questions were tested with a binomial test and Wilcoxon signed test, which assumes independent observations, symmetry (about zero), and no ties [64]. The binomial tests show the possibility of occurrence of one of the two possible outcomes. In this research, it was used to see the respondent's point of view on the significance of dependent variables. The significance of each dependent variable in all cases were tested with a cut-off point set at 3 , which means all organizations are divided into two groups. First, is less than and equal to 3 , are those whose opinions are from very strong to moderate intense, and group 2 is greater than 3 , whose responses are from little to no when measured on the respective test scale. The test proportion was set at $50 \%$. On the other hand, the Wilcoxon sign test showed if the mean rank of two related samples differ, or in other words, it allows the analysis of matched-pair data, based on differences, or for a single sample [65]. In this research, this test was used to see which dependent variables have more or less significant impact within same group, when compared to other variables by comparing signs and mean values. In addition to above mentioned statistical tests, a descriptive analysis was completed to see the respondents view point on a maturity time line for innovative technologies. The data was analyzed using statistical software SPSS. 


\section{Results}

In this section, answers to the research questions have been discussed based on the responses collected using the online survey.

\subsection{Expected Maturity Time Line of Innovative Technologies}

In pursuit of understanding a realistic timeline for maturity of technologies like autonomous vehicles, Internet of things and big data, all of the participating organizations were asked, when they think the above mentioned technologies would be mature enough (from pilot to full operational level) to be implemented on highways in their respective regions. Figure 2 below highlights the respondents' feedback to this question.

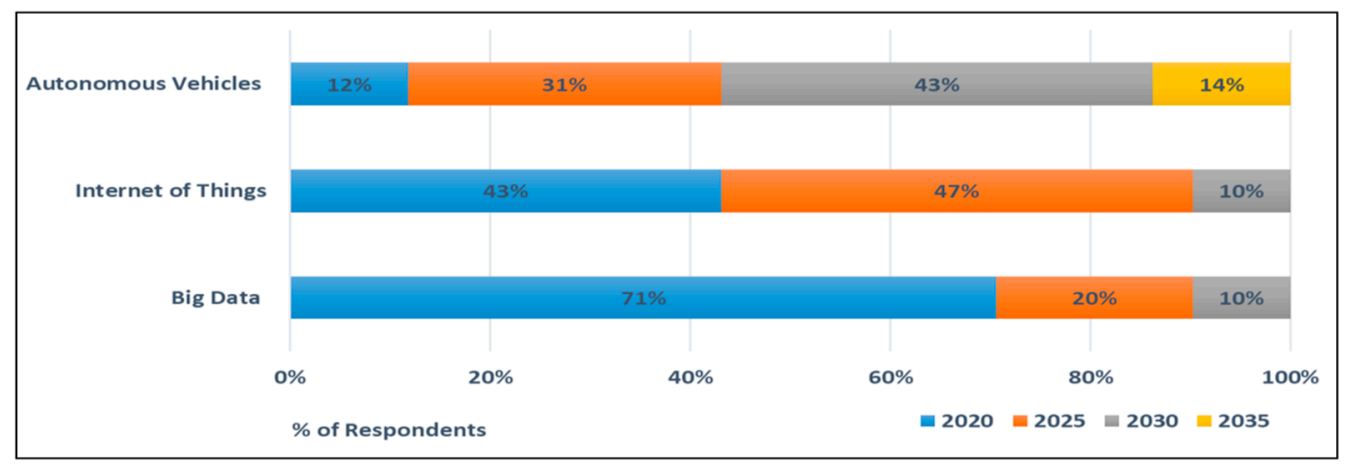

Figure 2. Innovative technologies expected maturity time line.

As can be seen from the figure above that out of 51 respondents, the majority (36) postulated that big data would be actively placed in operations by 2020, and only 15 believed it could take another 5 to 10 years to be mature enough for highway operations. According to the responses, the Internet of thing is the second rapidly maturing technological advancement. The results show that 22 organizations think it could be in highway operations by 2020 whereas, 24 believe it would take another 5 years to play its role in highway operations, and only 5 organizations believe it would not be actively used until 2030 in highway operations. The opinions on AV are divided into two equal halves-22 organizations believe that AV technology would mature by 2025 or earlier, and 22 organizations deem it would take another five years to be on the roads. Although, 7 of respondents believe this technological advancement would mature until 2035.

There are two main regions, which responded to this survey, i.e., North America (N.A.) and European Union (E.U.) with 35 and 11 respondents respectively, which makes 90\% of the total responding organizations. Whereas, only five organizations have responded from Asia, South America and other regions combined. Therefore, for the sake of simplicity, in Table 3 below, this study compared and discussed only two main groups of responding organizations.

Table 3. Innovative technologies maturity time-line North America v/s European Union.

\begin{tabular}{|c|c|c|c|c|c|c|c|c|c|c|c|}
\hline & Year & N.A. & E.U. & & Year & N.A. & E.U. & & Year & N.A. & E.U. \\
\hline \multirow{4}{*}{$\begin{array}{l}\text { Internet of } \\
\text { Things }\end{array}$} & 2020 & $43 \%$ & $45 \%$ & \multirow{4}{*}{ Big Data } & 2020 & $63 \%$ & $91 \%$ & \multirow{4}{*}{$\begin{array}{l}\text { Autonomous } \\
\text { Vehicles }\end{array}$} & 2020 & $11 \%$ & $9 \%$ \\
\hline & 2025 & $43 \%$ & $55 \%$ & & 2025 & $23 \%$ & $9 \%$ & & 2025 & $34 \%$ & $27 \%$ \\
\hline & 2030 & $14 \%$ & $0 \%$ & & 2030 & $14 \%$ & $0 \%$ & & 2030 & $40 \%$ & $55 \%$ \\
\hline & 2035 & $0 \%$ & $0 \%$ & & 2035 & $0 \%$ & $0 \%$ & & 2035 & $14 \%$ & $9 \%$ \\
\hline
\end{tabular}

The majority of the organizations believe that Internet of things and big data would be adaptable for highway operations in their countries at the latest by 2025. Only a small number of organizations think it might take another five years. Organizations from both regions have a similar view on 
autonomous vehicles, which is one of the most discussed topics over the past few years. Further, $44 \%$ and $36 \%$ of the North American and European organizations believe self-driving cars would be completed at the latest by 2025 . However, $40 \%$ of the North American and $55 \%$ of the European organizations think they would see AVs in operation by 2030 . Only $14 \%$ and $9 \%$ of the organizations, respectively, think it might take another 5 years to be mature enough for adaptation.

\subsection{Autonomous Vehicles on Highways in Next 10 Years}

It is very crucial to understand the transition from conventional cars to autonomous vehicles. There would be a time where both cars will have almost equal percentage when driving on the highways, but what matters most is the time line when it is expected to happen. It would allow the organizations involved in highway operations to plan for the upcoming future in a better way and adjust their business dynamics. In this survey, the responding organizations were asked to enlighten us with their opinion on what they think the situation might be in next 10 years. Figure 3 below reflects their opinions in numbers.

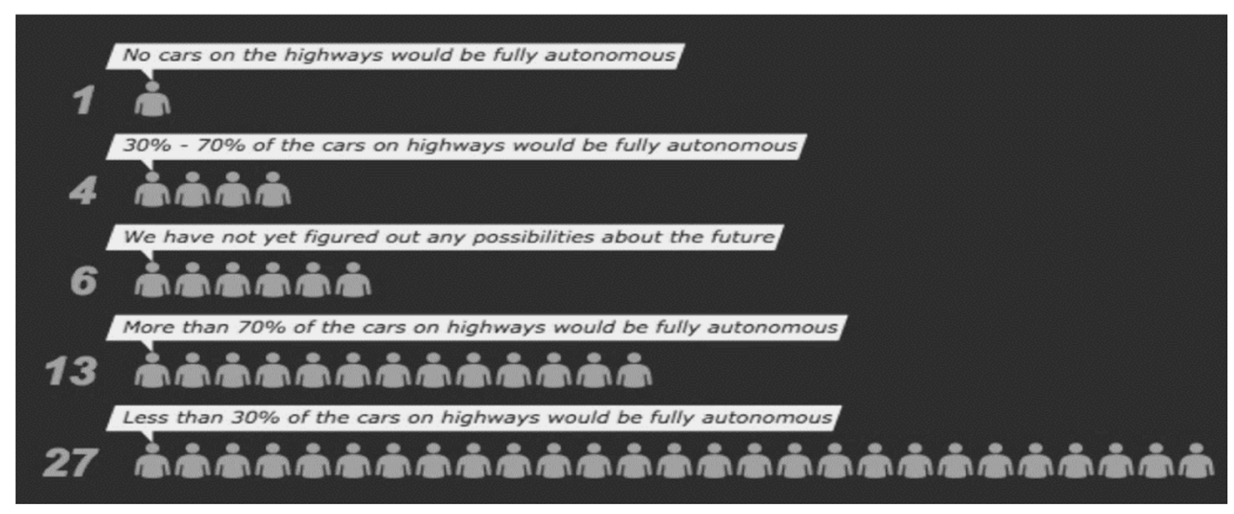

Figure 3. Autonomous Vehicle scenarios until 2030.

It is observed that majority of the responding organizations are being optimist about the fact that self-driving vehicles (vehicles automation level 4 and $5[15,16]$ ) will show an exponential growth. The data shows that over $52 \%$ of respondents predict less than or equal to $30 \%$ vehicles to be autonomous by 2030 . Whereas, $33 \%$ of organizations predict this to be more than $30 \%$, although how much more varies significantly. However, the percentage of agreement might differ between organizations, but the majority of the organizations agree on the point that the autonomous vehicle revolution is imminent, many more cars will be autonomous and there should be measures in place to accommodate them.

\subsection{Potential Business Transformations}

In order to understand how existing business models for highway and toll operators might change in the future, as autonomous vehicles replace the conventional cars. Three arbitrary business options were formulated bearing in mind the different levels of autonomous vehicle proportions on the highways. The respondents had a choice of three business models out of which, one is traditional and two are conceptual futuristic business models:

\subsubsection{B1—Pure Infrastructure Provider}

The highway and toll operator should strictly concentrate on the building, maintenance and operations of highways. This is an orthodox business model, which has been in existence for a long time, and a big number of highway operators already follow this approach. 


\subsubsection{B2-Infrastructure Provider with Highly Developed Information Skills}

In addition to B1, the highway and toll operators are expected to analyze all the information about traffic flows, usage or rest areas, usage of charging station etc., collected from several data points. For example, SAT NAV systems, cameras and other sensors embedded in highways for amalgamated billing/tolling, better traffic management and enhanced safety and security. Generally, the information skills are not in-house but outsourced.

\subsubsection{B3-Highway 4.0 Operator}

In addition to B1 and B2, the highway operator is expected to actively control the traffic e.g., by organizing trucks and cars platooning on the highway, organizing distribution slots for traveling and parking, and operating hubs where goods can be transferred from larger carriers to smaller ones, etc. In general, this model allows highway operators to take control of end-to-end highway activities, resulting in acquiring all the skills needed for such operations in house instead of outsourcing. It is perceived that in the future, data collected from several data points would also be considered as an asset and therefore, it will add much value to an organization's operations.

Figure 4 below reflects the opinion of respondents on business model selection and paradigm shift of highway operators as future dynamics of highway operations change.

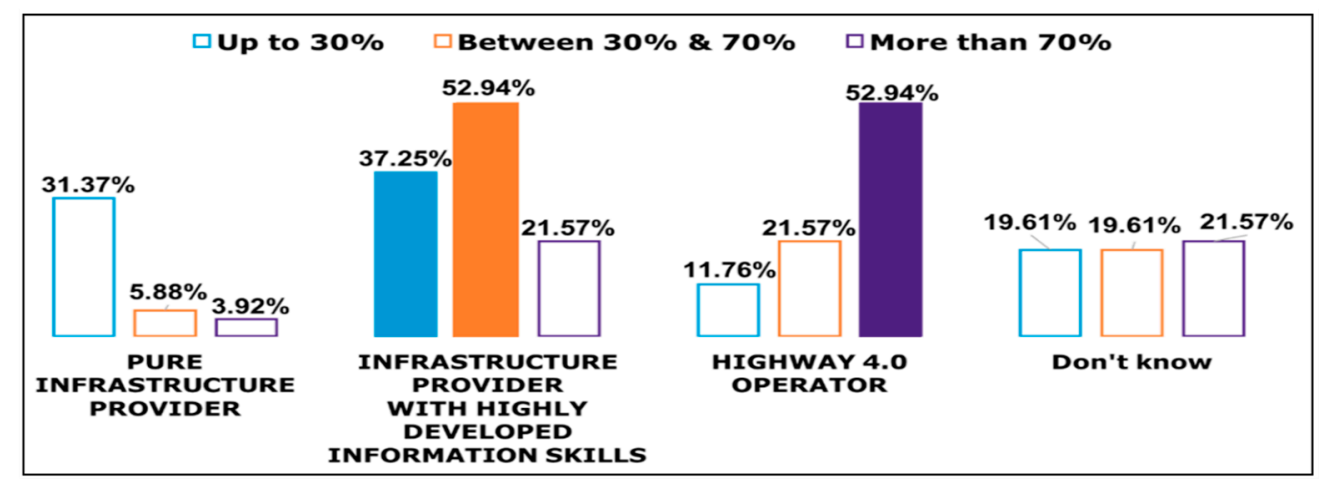

Figure 4. Potential business transformations.

The respondents seem to be inclined to adapt to the $\mathrm{B} 2$ business model as autonomous vehicles reach to the level of $30 \%$, which is highly likely to happen by 2030 as discussed in the preceding subheading. However, approximately $31 \%$ of respondents voted to adhere to the orthodox business model (B1) and approximately $20 \%$ stated they do not know which model they should choose. Approximately 53\% would still like to stay as the infrastructure provider with highly developed information skills as the percentages of autonomous cars on highways fluctuates between $30 \%$ and $70 \%$. Approximately $22 \%$ of respondents would like to adapt to the B3 business model at this stage, and approximately $20 \%$ were not sure which model to choose. Approximately $53 \%$ are likely to choose the B3 business model and approximately $22 \%$ would stay with the B2 business model. A slight percentage of approximately $4 \%$ would still like to stay at B1, whereas, approximately $22 \%$ are not sure to what they would choose.

It can be seen that as the number of autonomous vehicles increases on the highways, it is highly likely that highways and toll operators would switch from existing traditional business models to the newer ones in order stay competitive. It will not only allow them to stay in competition, but also to earn extra revenues by facilitating travelers in several different ways and charge for the additional services provided. 


\subsection{Big Data's Impact on Highway Route Planning, Throughput and Bottlenecks}

Big data is one of the rapidly advancing technologies in today's world and respondents of this survey seem to verify this statement. It is very important to understand some dynamics of this technology, which could assist highway operators in developing highways that are more fluid than ever before. The results in Table 4 highlight the understanding of respondents about how they think this technological advancement will help in three specific areas i.e., better route planning, increasing highway throughput and mitigating bottlenecks. The results for binomial tests suggest that in all three cases, more than $90 \%$ of participating organizations agree that there is a big potential for big data application in highway operations, especially in these three areas. Using several data points as discussed by Herrera et al. [58], this technology will help in improving route planning, increase highway throughput and help in mitigating highway bottlenecks. However, when compared to the importance of each parameter within the group using the Wilcoxon sign rank test in Table 5, the responses suggest, based on the significance value of greater than 0.05 , that in all cases of these three parameters, no one parameter is more important than other within the group. However, with a value of 0.068 , big data is most likely to help in better route planning compared to an increase in highway throughput and mitigating bottlenecks.

Table 4. Binomial test (Statistics) for Big Data.

\begin{tabular}{cccccc}
\hline & & Category & N & Observed Prop. & Exact Sig. (2-Tailed) \\
\hline Route & Group 1 & $<=3$ & 47 & 0.94 & \\
Planning & Group 2 & $>3$ & 3 & 0.06 & 0.000 \\
& Total & & 50 & 1.00 & \\
\hline \multirow{2}{*}{ Highway } & Group 1 & $<=3$ & 48 & 0.94 & 0.000 \\
Throughput & Group 2 & $>3$ & 3 & 0.06 & \\
& Total & & 51 & 1.00 & 0.000 \\
Mitigating & Group 1 & $<=3$ & 47 & 0.92 & \\
Bottlenecks & Group 2 & $>3$ & 4 & 0.08 & \\
& Total & & 51 & 1.00 & \\
\hline
\end{tabular}

Table 5. Wilcoxon Sign rank test (Statistics) Big Data.

\begin{tabular}{cccc}
\hline & $\begin{array}{c}\text { Route Planning V/S } \\
\text { Mitigating Bottlenecks }\end{array}$ & $\begin{array}{c}\text { Highway Throughput } \\
\text { V/S Route Planning }\end{array}$ & $\begin{array}{c}\text { Highway Throughput V/S } \\
\text { Mitigating Bottlenecks }\end{array}$ \\
\hline $\mathrm{Z}$ & $-1.828^{\mathrm{a}}$ & $-1.235^{\mathrm{b}}$ & $-1.091^{\mathrm{a}}$ \\
\hline Asymp. Sig. (2-tailed) & 0.068 & 0.217 & 0.275 \\
\hline
\end{tabular}

\subsection{Internet of Things' Impact on Toll Collection, Highway RTC and Traffic Management}

As the Internet of things has started to play an active role in our day-to-day life, it is expected that it has a potential to transform conventional ways of doing business on highways. Table 6 shows that over $90 \%$ of the seasoned respondents of this survey, who excel in their field believe that the Internet of things can revolutionize the conventional ways of collecting toll tax. As more and more vehicles will be connected to the Internet, it will be easier to trace and deduct tolls for the usage of highways from point A to B. Moreover, $98 \%$ of respondents are convinced that the Internet of things will assist in highway real time communication (RTC) and traffic management. Highway real-time communication refers to the instant disbursement of information in real time using the Internet of things technology. This will help the network of connected and autonomous automobiles use several data points. For example, the information about weather, accidents and change in speed limits, congestion or other emergencies could be transmitted in real time, hence, letting the vehicles reroute their itinerary. IoT will also help in better traffic management on highways in order to keep up with time. It can also result in different 
tolling strategies by evenly distributing the traffic by enforcing higher toll rates during congestion hours. This could result in variable peak and off-peak times and the vehicles would be informed about such changes via RTC. Moreover, when tested for the importance of each variable within the group via the Wilcoxon signed rank test in Table 7, it became obvious that highway operators tend to believe the Internet of things will prove to be of more assistance compared to highway RTC and traffic management on highways. Highway RTC and traffic management are important, but when compared with one another, their significance is higher than 0.05 . Thus, it shows that the Internet of things will have equal impact on both highway RTC and traffic management on highways. However, according to the experts, there will be a significant impact of the Internet of things on toll collection on highways.

Table 6. Binomial test (Statistics) for IOT.

\begin{tabular}{|c|c|c|c|c|c|c|}
\hline & & Category & $\mathbf{N}$ & Observed Prop. & Test Prop. & $\begin{array}{l}\text { Exact Sig. } \\
\text { (2-Tailed) }\end{array}$ \\
\hline \multirow{3}{*}{$\begin{array}{c}\text { Toll } \\
\text { Collection }\end{array}$} & Group 1 & $<=3$ & 46 & 0.9 & 0.5 & \multirow{3}{*}{0.000} \\
\hline & Group 2 & $>3$ & 5 & 0.1 & & \\
\hline & Total & & 51 & 1 & & \\
\hline \multirow{3}{*}{$\begin{array}{l}\text { Highway } \\
\text { RTC }\end{array}$} & Group 1 & $<=3$ & 50 & 0.98 & 0.5 & \multirow{3}{*}{0.000} \\
\hline & Group 2 & $>3$ & 1 & 0.02 & & \\
\hline & Total & & 51 & 1 & & \\
\hline \multirow{3}{*}{$\begin{array}{c}\text { Traffic } \\
\text { Management }\end{array}$} & Group 1 & $<=3$ & 50 & 0.98 & 0.5 & \multirow{3}{*}{0.000} \\
\hline & Group 2 & $>3$ & 1 & 0.02 & & \\
\hline & Total & & 51 & 1 & & \\
\hline
\end{tabular}

Table 7. Wilcoxon Signed-rank test (Statistics) for IOT.

\begin{tabular}{cccc}
\hline & $\begin{array}{c}\text { Toll Collection V/S } \\
\text { Highway RTC }\end{array}$ & $\begin{array}{c}\text { Toll Collection V/S } \\
\text { Traffic Management }\end{array}$ & $\begin{array}{c}\text { Highway RTC V/S } \\
\text { Traffic Management }\end{array}$ \\
\hline $\mathrm{Z}$ & $-2.433^{\mathrm{a}}$ & $-2.922^{\mathrm{a}}$ & $-1.732^{\mathrm{a}}$ \\
\hline Asymp. Sig. (2-tailed) & 0.015 & 0.003 & 0.083 \\
\hline
\end{tabular}

\subsection{Impact of Connected Vehicles on Traffic Management in Rural, Urban and Highway Roads}

Organizations were asked for their opinion on the impact of the increasing number of connected vehicles on traffic management in three different regions, namely highways, urban areas and rural areas. The binomial test in Table 8 with a significance value of $0.78>0.05$ (for rural areas) confirm that respondents believe there would be no significant impact on rural areas traffic management with the induction of connected vehicles. However, the impact on highways and urban areas will be otherwise. Furthermore, the Wilcoxon sign rank test in Table 9 confirms that participating organizations agree on a positive impact of connected vehicles on highways and urban areas. The test results show that connected vehicles would have a positive impact on urban areas when compared to rural areas (Sig. Value $0.00<0.05$ ) and it shows similar results for highways when compared to rural areas. However, when compared within the group, highways and urban areas (sig. value $0.310>0.05$ ) show that there would be a positive impact on traffic management in both regions. It is expected that CVs would lead to noticeable reduction in congestion and capacity challenges and result in smooth traffic management, especially in these two regions. In rural areas, there would be little to no effect, which means there would be barely any reduction in congestion and capacity challenges compared to the present traffic condition. The possible reason could be that the augmented number of people are moving to urban areas leaving rural areas less populated. Less population means less vehicles and subsequently less impact on traffic management in the future, when compared to the present time. 
Table 8. Binomial test (Statistics) for connected vehicles.

\begin{tabular}{|c|c|c|c|c|c|c|}
\hline & & Category & $\mathbf{N}$ & Observed Prop. & Test Prop. & $\begin{array}{l}\text { Exact Sig. } \\
\text { (2-Tailed) }\end{array}$ \\
\hline \multirow{3}{*}{ Rural Areas } & Group 1 & $<=3$ & 24 & 0.47 & 0.5 & \multirow{3}{*}{0.780} \\
\hline & Group 2 & $>3$ & 27 & 0.53 & & \\
\hline & Total & & 51 & 1 & & \\
\hline \multirow{3}{*}{ Urban Areas } & Group 1 & $<=3$ & 49 & 0.96 & 0.5 & \multirow{3}{*}{0.000} \\
\hline & Group 2 & $>3$ & 2 & 0.04 & & \\
\hline & Total & & 51 & 1 & & \\
\hline \multirow{3}{*}{ Highways } & Group 1 & $<=3$ & 49 & 0.96 & 0.5 & \multirow{3}{*}{0.000} \\
\hline & Group 2 & $>3$ & 2 & 0.04 & & \\
\hline & Total & & 51 & 1 & & \\
\hline
\end{tabular}

Table 9. Wilcoxon sign test (statistics) for connected vehicles.

\begin{tabular}{cccc}
\hline & Urban Area/Rural Areas & Highways/Rural Areas & Highways/Urban Areas \\
\hline$Z$ & $-5.364^{\mathrm{a}}$ & $-5.640^{\mathrm{a}}$ & $-1.014^{\mathrm{a}}$ \\
\hline Asymp. Sig. (2-tailed) & 0.00 & 0.00 & 0.310 \\
\hline \multicolumn{4}{c}{ a Based on positive ranks. }
\end{tabular}

\subsection{Impact of Autonomous Vehicles on Highways in Terms of Road Accidents, Traffic Volumes and Toll Pricing}

To understand the impact of autonomous vehicles on highways in terms of road accidents, traffic volumes and toll pricing, research studies created a scenario that until 2030 , at least $30 \%$ of all vehicles on highways would be fully autonomous and organizations were supposed to answer this question in light of the given scenario. The binomial test results in Table 10 clearly indicate that $30 \%$ of autonomous vehicles on highways until 2030 will have no effect on toll pricing (Sig value. $0.392>0.05$ ) and they are most likely to stay as it is. However, this scenario will have a positive impact on road safety and traffic volumes mostly because autonomous vehicles are more intelligent and smarter than human drivers thus resulting in better road safety. These vehicles would be able to make multiple trips as restrictions on driving bans for such cars will be lifted and thus increasing the traffic volume on highways. Autonomous vehicles would play an important role in mitigating capacity utilization and congestion issues of highways in the future [12]. However, in early phase (2030), self-driving cars would possibly result in the reduction of accidents on highways, but not total elimination.

Table 10. Binomial test (Statistics) for autonomous vehicles on highways.

\begin{tabular}{ccccccc}
\hline & & Category & N & Observed Prop. & Test Prop. & $\begin{array}{l}\text { Exact Sig. } \\
\text { (2-Tailed) }\end{array}$ \\
\hline \multirow{3}{*}{ Road Safety } & Group 1 & $<=3$ & 46 & 0.9 & 0.5 & \\
& Group 2 & $>3$ & 5 & 0.1 & & 0.000 \\
& Total & & 51 & 1 & & \\
\hline \multirow{2}{*}{ Traffic } & Group 1 & $<=3$ & 36 & 0.72 & 0.5 & \multirow{2}{*}{0.003} \\
Volumes & Group 2 & $>3$ & 14 & 0.28 & & \\
& Total & & 50 & 1 & 0.5 & 0.392 \\
\multirow{2}{*}{ Toll Pricing } & Group 1 & $<=3$ & 28 & 0.57 & & \\
& Group 2 & $>3$ & 21 & 0.43 & & \\
& Total & & 49 & 1 & & \\
\hline
\end{tabular}

When compared to the importance of each factor within the group by the Wilcoxon signed rank test, Table 11, it is observed that all three factors are important and no one factor will have a more significant impact due to $30 \%$ of autonomous vehicles on highways when compared to others. 
Table 11. Wilcoxon sign test (statistics) for autonomous vehicles on highways.

\begin{tabular}{cccc}
\hline & $\begin{array}{c}\text { Traffic Volumes/Road } \\
\text { Safety }\end{array}$ & $\begin{array}{c}\text { Toll Pricing/Road } \\
\text { Safety }\end{array}$ & $\begin{array}{c}\text { Toll Pricing/Traffic } \\
\text { Volumes }\end{array}$ \\
\hline$Z$ & $-3.635^{\mathrm{a}}$ & $-4.646^{\mathrm{a}}$ & $-2.743^{\mathrm{a}}$ \\
\hline Asymp. Sig. (2-tailed) & 0.000 & 0.000 & 0.006 \\
\hline & \multicolumn{2}{c}{${ }^{\mathrm{a}}$ based on positive ranks. }
\end{tabular}

\subsection{Critical Investments Required to Facilitate Autonomous Vehicles on Highways}

Highway operators like many others, shall be prepared to invest to make highways compatible with modern technology and advance vehicle systems that would ascend as technological advancements overtake conventional systems. Out of several possible potential critical investment areas, in this section, studies have primarily focused on three basic but key potential possibilities. These are, investments in hardware infrastructure, software infrastructure and road signs/boards or markings. Organizations were asked for their view point on these three potential challenges, considering the same scenario as mentioned in 4.7 ( $30 \%$ vehicles on road are autonomous by 2030$)$.

The results of binomial tests in Table 12 show that the respondents seem to agree that all three areas of investment are critical. These investments will aid autonomous vehicles, and at the same time, the investment in computer hardware (like routers, relays and cameras etc.) and software infrastructure would enable them to provide IoT and big data related services. However, road signs/boards and markings would be purely for assistive purposes for autonomous vehicles (cars/trucks). In addition, this will also give highway operators and concessioners a competitive edge over other service providers, thus, resulting in some new sort of business opportunity as discussed by Azmat et al. [12]. Moreover, when compared to the importance of each variable within the group using the Wilcoxon signed rank test in Table 13, it is observed that hardware and software infrastructure investments are the most critical ones $(0.20>0.05)$. Investments related to road signs/boards and markings are less critical when compared to other two $(0.00<0.05)$.

Table 12. Binomial test (Statistics) for critical investments required to facilitate AV.

\begin{tabular}{|c|c|c|c|c|c|c|}
\hline & & Category & $\mathbf{N}$ & Observed Prop. & Test Prop. & $\begin{array}{l}\text { Exact Sig. } \\
\text { (2-Tailed) }\end{array}$ \\
\hline \multirow{3}{*}{$\begin{array}{l}\text { Hardware } \\
\text { Infrastructure }\end{array}$} & Group 1 & $<=3$ & 45 & 0.9 & 0.5 & \multirow{3}{*}{0.000} \\
\hline & Group 2 & $>3$ & 5 & 0.1 & & \\
\hline & Total & & 50 & 1 & & \\
\hline \multirow{3}{*}{$\begin{array}{c}\text { Software } \\
\text { Infrastructure }\end{array}$} & Group 1 & $<=3$ & 46 & 0.92 & 0.5 & \multirow{3}{*}{0.000} \\
\hline & Group 2 & $>3$ & 4 & 0.08 & & \\
\hline & Total & & 50 & 1 & & \\
\hline \multirow{3}{*}{$\begin{array}{l}\text { Road Signs } \\
\text { \& Boards }\end{array}$} & Group 1 & $<=3$ & 40 & 0.8 & 0.5 & \multirow{3}{*}{0.000} \\
\hline & Group 2 & $>3$ & 10 & 0.2 & & \\
\hline & Total & & 50 & 1 & & \\
\hline
\end{tabular}

Table 13. Wilcoxon sign test (statistics) for critical investments required to facilitate AV.

\begin{tabular}{cccc}
\hline & $\begin{array}{c}\text { Software } \\
\text { Infrastructure/Hardware } \\
\text { Infrastructure }\end{array}$ & $\begin{array}{c}\text { Hardware } \\
\text { Infrastructure/Road } \\
\text { Signs \& Boards }\end{array}$ & $\begin{array}{c}\text { Software } \\
\text { Infrastructure/Road } \\
\text { Signs \& Boards }\end{array}$ \\
\hline $\mathrm{Z}$ & $-2.333^{\mathrm{a}}$ & $-4.224^{\mathrm{b}}$ & $-4.674^{\mathrm{b}}$ \\
\hline Asymp. Sig. (2-tailed) & 0.020 & 0.000 & 0.000 \\
\hline & ${ }^{a}$ a based on positive ranks. ${ }^{\mathrm{b}}$ Based on negative ranks.
\end{tabular}




\section{Conclusions}

This exploratory research highlights the potential applications, and use-case scenarios for the buzzwords in innovative technologies like autonomous/connected vehicles, the Internet of things and big data. These technological advancements are not far from reality, and the change is happening at an exponential rate. Responses were collected from seasoned professionals from more than fifty organizations worldwide which are actively or passively involved in highway operation/consultation. It is of utter need to explore these technological advancements and see their potential impact on different business sectors. One such sector is highways and highway operations. It is important to understand how conventional highways or highway operations will be affected by these new technological advancements. Highways play a pivotal role in day to day life as they are one of the most used transportation modes on the ground. Highways not only help in efficient and sustainable commuting, but also allow a connection to remote rural areas to urban societies. However, the results have shown that advancements in mobility with induction of autonomous vehicles or connected vehicles would not be of great help in already underutilized rural country roads or highways, but its impact would be visible on highways connecting urban areas and urban roads.

Moreover, the Internet of things and big data would also positively affect the highway operations, be it by providing critical information in real time, by communicating with technologically equipped vehicles using modern state of the art infrastructure or by helping commuters avoid congestion zones. It would result in reduced emissions on highways and more sustainable and cleaner environments surrounding highways. As society is moving towards a gasoline free era, it is expected that cars in the future will be mostly electric which means, it will also help reduce the costs related to transport externalities. Moreover, this paper serves as a guide for highway operators who are interested in preparing themselves for the future and design long term policies. Highway operators and tolling agencies should prepare themselves for the beginning of new era, which will bring with it several opportunities and challenges. Between 2020 and 2030, a revolution in transport technology is highly expected, which would have a direct impact on highway and toll operators. The technologies like connected vehicles, big data and the Internet of things would help highway operators to manage traffic more efficiently and effectively, but at the same time, they would be expected to provide safe and secure networks for both the internet and intranet so that these technologies are used to the best of their potential. It is also an important fact that as more and more vehicles would become autonomous, the tendency to change the existing way of doing business will change dramatically. It is important for highway operators and tolling organizations to brace for the change as it would eventually become their competitive advantage. It is highly likely that more and more highway operators will adapt to highway 4.0 operators as autonomous vehicles become more and more popular and affordable.

Lastly, it has also been observed from the literature review and the findings of this research that many of these technologies tend to reap similar results. While their applications might be different from one another, the expected output is more or less the same. For instance, the Internet of things, big data, connected or autonomous vehicles seem promising when it is about reduction in congestion, real time information, reduction in accidents caused on highways or in urban areas, etc. It also tells us that these technologies are fit to work in conjunction with one another and support each other to enhance the outcome.

Author Contributions: Conceptualization, M.A., S.K., L.T.M., F.D.G., R.M.; data curation, L.T.M., F.D.G., R.M.; formal analysis, M.A.; funding acquisition, M.A., S.K., L.T.M., F.D.G., R.M.; investigation, M.A., R.M.; methodology, M.A.; project administration, S.K., M.A., R.M.; supervision, S.K.; validation, M.A.; visualization, M.A.; writing—original draft, M.A.; writing—review \& editing, M.A., S.K., R.M., F.D.G.

Funding: This research was funded by the following organizations under grant number 270001320 (WU).

- $\quad$ Autobahnen- und Schnellstraßen-Finanzierungs-Aktiengesellschaft (ASFINAG, Austria);

- Associazione Italiana Società Concessionarie Autostrade e Tarfori (AISCAT, Italy);

- Inovação Quinta Da Torre Da Aguilha-Edifício Brisa (A-to-Be, Portugal). 
Acknowledgments: Authors of this research would like to thank Patrick D. Jones of International Bridge, Tunnel and Turnpike Association (IBTTA, USA) for his unconditional support in distributing the survey to more than 200-member organizations worldwide.

Conflicts of Interest: The authors declare no conflicts of interest.

\section{References}

1. Mahmassani, H.S. Autonomous Vehicles and Connected Vehicle Systems: Flow and Operations Considerations. Transp. Sci. 2016, 50, 1140-1162. [CrossRef]

2. Clausen, U.; Holloh, K.; Kadow, M. Visions of the Future: Transportation And Logistics 2030. In Examining the Potential for the Development of Road and Rail Transportation to 2030; Fraunhofer, I.M.L., Daimler, A.G., Eds.; DB Mobility Logistics AG: Berlin, Germany, 2014.

3. Fagnant, D.J.; Kockelman, K. Preparing A Nation for Autonomous Vehicles: Opportunities, Barriers and Policy Recommendations. Transp. Res. Part A 2015, 77, 167-181. [CrossRef]

4. Gerla, M.; Lee, E.K.; Pau, G.; Lee, U. Internet of Vehicles: From Intelligent Grid to Autonomous Cars and Vehicular Clouds. In Proceedings of the IEEE World Forum on Internet of Things (Wf-Iot), Seoul, South Korea, 6-8 March 2014; pp. 241-246.

5. Michail, M.; Konstantinos, M.; Biagio, C.; María, A.R.; Christian, T. Assessing the Impact of Connected and Automated Vehicles. A Freeway Scenario. In Advanced Microsystems For Automotive Applications 2017; Springer: Cham, Switzerland, 2018.

6. Miorandi, D.; Sicari, S.; Pellegrini, F.D.; Chlamtac, I. Internet of Things: Vision, Applications and Research Challenges. Ad Hoc Netw. 2012, 10, 1497-1516. [CrossRef]

7. Shi, Q.; Abdel-Aty, M. Big Data Applications in Real-Time Traffic Operation and Safety Monitoring and Improvement on Urban Expressways. Transp. Res. Part C 2015, 58, 380-394. [CrossRef]

8. Schaefer, A.; Heywood, J.B.; Jacoby, H.D.; Watiz, I.A. Transportation in A Climate-Constrained World; MIT press: London, UK, 2009.

9. Kpmg, C.; Silberg, G.; Wallace, R.; Matuszak, G.; Plessers, J.; Brower, C.; Subramanian, D. Self-Driving Cars: The Next Revolution; Kpmg: Seattle, WA, USA, 2012.

10. Utah Department of Transportation (Udot). Best Practices for Regulation of Autonomous Vehicles on Utah Highways; Utah Deaprtment of Public Safety: Salt Lake City, UT, USA, 2016.

11. Bierstedt, J.; Gooze, A.; Gray, C.; Peterman, J.; Raykin, L.; Walters, J. Effects of Next Geberation Vehicles on Travel Demand and Highway Capacity; Fehr and Peers: Washington, DC, USA, 2014.

12. Azmat, M.; Kummer, S.; Moura, L.T.; Gennaro, F.D.; Moser, R. Impact of Innovative Technologies on Highway Operators: Tolling Organizations' Perspective. In Proceedings of the Transport Research Arena, Vienna, Austria, 16-19 April 2018.

13. Merki, C. Verkehrsgeschichte Und Mobilität; Ulmer: Stuttgart, Germany, 2008.

14. Azmat, M.; Schuhmayer, C.; Kummer, S. Innovation in Mobility: Austrian Expert's Perspective on the Future of Urban Mobility with Self-Driving Cars. In Proceedings of the Innovation Arabia: Quality and Business Management Conference, Dubai, UAE, 19 May 2016.

15. National Highway Traffic Safety Administration. Preliminary Statement of Policy Concerning Automated Vehicles; Nhtsa: Washington, DC, USA, 2013.

16. Nhtsa. Automated Vehicles for Safety. Nhtsa, 2018. Available online: https://www.Nhtsa.Gov/TechnologyInnovation/Automated-Vehicles-Safety (accessed on 20 April 2019).

17. Rosenzweig, J.; Bartl, M. A Review and Analysis of Literature on Autonomous Driving. 2015, pp. 1-57. Available online: http://www.michaelbartl.com/article/a-review-and-analysis-of-literature-on-autonomousdriving/ (accessed on 18 June 2019).

18. Maurer, M.; Gerdes, J.C.; Lenz, B.; Winner, H. Autonomes Fahren: Technische, Rechtliche Und Gesellschaftliche Aspekte; Springer: Berlin, Germany, 2015.

19. Choi, T.; Wallace, S.W.; Wang, Y. Big Data Analytics in Operations Management. Prod. Oper. Manag. 2017, 27, 1868-1883. [CrossRef]

20. Litman, T. Autonomous Vehicle Implementation Predictions: Implications for Transport Planning; Victoria Transport Policy Institute: Victoria, BC, Canada, 2015. 
21. Kyriakidis, M.; Happee, R.; Winter, J.D. Public Opinion on Automated Driving: Results of an International Questionnaire among 5000 Respondents. Transp. Res. Part F Traffic Psychol. Behav. 2015, 32, 127-140. [CrossRef]

22. Milakis, D.; Snelder, M.; van Arem, B.; van Wee, B.; de Almeida Correia, G.H. Development and Transport Implications of Automated Vehicles in the Netherlands: Scenarios for 2030 and 2050. Eur. J. Transp. Infrastruct. Res. 2017, 17, 63-85.

23. Gkartzonikas, C.; Gkritza, K. What Have We Learned? A Review of Stated Preference and Choicestudies on Autonomous Vehicles. Transp. Res. Part C 2019, 98, 323-337. [CrossRef]

24. Milakis, D.; Arem, B.V.; Wee, B.V. Policy and Society Related Implications of Automated Driving: A Review of Literature and Directions for Future Research. J. Intell. Transp. Syst. 2017, 21, 324-348. [CrossRef]

25. Lu, N.; Cheng, N.; Zhang, N.; Shen, X.; Mark, J.W. Connected Vehicles: Solutions and Challenges. IEEE Internet Things J. 2014, 1, 289-299. [CrossRef]

26. Kanchanasut, K.; Boonsiripant, S.; Tunpan, A.; Kim, H.K.; Ekpanyapong, M. Internet of Cars Through Commodity V2v and V2x Mobile Routers: Applications for Developing Countries. Ksce J. Civil Eng. 2015, 19, 1897-1904. [CrossRef]

27. Mosquet, X.; Andersen, M.; Arora, A. A Roadmap to Safer Driving Through Advanced Driver Assistance Systems; Bcg \& Mema: Washington, DC, USA, 2015.

28. Ezell, S. Intelligent Transportation Systems; The Information Technology \& Innovation Foundation (Itif): Washington, DC, USA, 2010.

29. Cregge, J. International Survey of Best Practices in Connected and Automated Vehicle Technologies; Mdot \& Car: Wixom, MI, USA, 2015.

30. Glielmo, L. Vehicle-to-Vehicle/Vehicle-to-Infrastructure Control. In The Impact of Control Technology. Overview, Success Stories, and Research Challenges; IEEE Control Systems Society: Munich, Germany, 2011; pp. 211-212.

31. Knapik, P.; Schoch, E.; Kargl, F. Electronic Decal: A Security Function Based on V2x Communication. In Proceedings of the 2013 IEEE 77th Vehicular Technology Conference (Vtc Spring), Dresden, Germany, 2-5 June 2013.

32. Muhammad, M.; Safdar, G.A. Survey on Existing Authentication Issues for Cellular-Assisted V2x Communication. Veh. Commun. 2018, 12, 50-65. [CrossRef]

33. Noori, H.; Valkama, M. Impact of Vanet-Based V2x Communication Using IEEE 802.11p on Reducing Vehicles Traveling Time in Realistic Large Scale Urban Area. In Proceedings of the 2013 International Conference on Connected Vehicles and Expo (Iccve), Las Vegas, NV, USA, 2-6 December 2013.

34. Trien, L.T.; Adachi, K.; Yamao, Y. Packet Relay-Assisted V2v Communication With Sectorised Relay Station Employing Payload Combining Scheme. IET Commun. 2018, 12, 458-465. [CrossRef]

35. Huang, C.-L.; Sengupta, R.; Krishnan, H.; Fallah, Y.P. Implementation and Evaluation of Scalable Vehicle-to-Vehicle Safety Communication Control. IEEE Commun. Mag. 2011, 49, 134-141. [CrossRef]

36. Wang, C.; He, M. Image Style Transfer With Multi-Target Loss for Lot Applications. In Proceedings of the 2018 15th International Symposium on Pervasive Systems, Algorithms and Networks (I-Span), Yichang, China, 16-18 October 2018.

37. Abdennour, Z.; Weijia, J. Heterogeneous Vehicular Communications: A Comprehensive Study. Ad Hoc Netw. 2018, 75, 52-79.

38. Butakov, V.A.; Ioannou, P. Personalized Driver Assistance for Signalized Intersections Using V2i Communication. IEEE Trans. Intell. Transp. Syst. 2016, 17, 1910-1919. [CrossRef]

39. Barrachina, J.; Garrido, P.; Fogue, M.; Martinez, F.J.; Cano, J.-C.; Calafate, C.T.; Manzoni, P. A V2i-Based Real-Time Traffic Density Estimation System in Urban Scenarios. Wirel. Pers. Commun. 2015, 83, 259-280. [CrossRef]

40. Dixit, M.; Kumar, R.; Sagar, A.K. Vanet: Architectures, Research Issues, Routing Protocols, and Its Applications. In Proceedings of the 2016 International Conference on Computing, Communication and Automation (Iccca), Noida, India, 29-30 April 2016.

41. Zhou, H.; Zhang, N.; Bi, Y.; Yu, Q.; Shen, X.S.; Shan, D.; Bai, F. Tv White Space Enabled Connected Vehicle Networks: Challenges and Solutions. IEEE Netw. 2017, 31, 6-13. [CrossRef]

42. Seo, H.; Lee, K.-D.; Yasukawa, S.; Peng, Y.; Sartori, P. Lte Evolution For Vehicle-to-Everything Services. IEEE Commun. Mag. 2016, 54, 22-28. [CrossRef] 
43. Gupta, N.; Prakash, A.; Tripathi, R. Clustering Based Cognitive Mac Protocol for Channel Allocation to Prioritize Safety Message Dissemination in Vehicular Ad-Hoc Network. Veh. Commun. 2016, 5, 44-54. [CrossRef]

44. Atzori, L.; Iera, A.; Morabito, G. The Internet of Things: A Survey. Comput. Netw. 2010, 54, $2787-2805$. [CrossRef]

45. Zhang, T.; Antunes, H.; Aggarwal, S. Defending Connected Vehicles against Malware: Challenges and a Solution Framework. IEEE Internet Things J. 2014, 1, 10-21. [CrossRef]

46. Press, G. A Very Short History of the Internet of Things. 14 June 2014. Available online: https://www.Forbes. Com/Sites/Gilpress/2014/06/18/A-Very-Short-History-of-the-Internet-of-Things/\#1a6c81f610de (accessed on 28 April 2019).

47. Chui, M.; Löffler, M.; Roberts, R. The Internet of Things, 2010. Available online: https://www.mckinsey.com/ industries/high-tech/our-insights/the-internet-of-things (accessed on 18 June 2019).

48. Greengard, S. The Internet of Things; Mit Press: London, UK, 2015.

49. Dong, H.; Wu, M.; Ding, X.; Chu, L.; Jia, L.; Qin, Y.; Zhou, X. Traffic Zone Division Based on Big Data from Mobile Phone Base Station. Transp. Res. Part C 2015, 58, 278-291. [CrossRef]

50. Al-Fuqaha, A.; Guizani, M.; Mohammadi, M.; Aledhari, M.; Ayyash, M. Internet of Things: A Survey on Enabling Technologies, Protocols, and Applications. IEEE Commun. Surv. Tutor. 2015, 17, 2347-2376. [CrossRef]

51. Tran, H. The Internet of Things and Potential Remedies in Privacy Tort Law. Columbia J. Law Soc. Probl. 2017, 50, 263-298. [CrossRef]

52. Bandyopadhyay, D.; Sen, J. Internet of Things: Applications and Challenges in Technology and Standardization. Wirel. Pers. Commun. 2011, 58, 49-69. [CrossRef]

53. Aktas, E.; Meng, Y. An Exploration of Big Data Practices in Retail Sector. Logistics 2017, 1, 12. [CrossRef]

54. Mayer-Schönberger, V.; Cukier, K. Big Data: A Revolution That Will Transform How We Live, Work, and Think; Houghton Mifflin Harcourt: Boston, MA, USA, 2013.

55. Mckinsey \& Company. Competing for the Connected Customer-Perspectives on the Opportunities Created By Car Connectivity and Automation, 2015. Available online: https://www.mckinsey.com/ \{\}/media/mckinsey/ industries/automotive\%20and\%20assembly/our\%20insights/how\%20carmakers\%20can\%20compete\%20for\% 20the\%20connected\%20consumer/competing_for_the_connected_customer.ashx (accessed on 18 June 2019).

56. Kellmereit, D.; Obodovski, D. The Silent Intelligence; DND Ventures: San Francisco, CA, USA, 2013.

57. Nash, B. History Channel, The Traffic, Modern Marvels Season 06 Episode 21: USA, 2000. Available online: https://www.youtube.com/watch?v=8BQCWN8_8d0\&list=PLcdD415qIvtvJA_ Ljdzl5pGVZbwKz03yW\&index=27 (accessed on 18 June 2019).

58. Herrera, J.C.; Work, D.B.; Herring, R.; Ban, X.; Jacobson, Q.; Bayen, A.M. Evaluation of Traffic Data Obtained Via Gps-Enabled Mobile Phones: The Mobile Century Field Experiment. Transp. Res. Part C 2010, 18, 568-583. [CrossRef]

59. Lu, H.-P.; Sun, Z.-Y.; Qu, W.-C. Big Data-Driven Based Real-Time Traffic Flow State Identification and Prediction. Hindawi Publ. Corp. Discret. Dyn. Nat. Soc. 2015, 2015, 284906. [CrossRef]

60. Hossain, M.; Muromachi, Y. A Bayesian Network Based Framework for Real-Time Crash Prediction on the Basic Freeway Segments of Urban Expressways. Accid. Anal. Prev. 2012, 45, 373-381. [CrossRef]

61. Pande, A.; Abdel-Aty, M. Assessment of Freeway Traffic Parameters Leading to Lane-Change Related Collisions. Accid. Anal. Prev. 2006, 38, 936-948. [CrossRef] [PubMed]

62. Jagadish, H.; Gehrke, J.; Labrinidis, A.; Papakonstantinou, Y.; Patel, J.M.; Ramakrishnan, R.; Shahabi, C. Exploring the Inherent Technical Challenges in Realizing the Potential of Big Data. Commun. ACM 2014, 57, 86-94. [CrossRef]

63. Meek, G.E.; Ozgur, C.; Dunning, K. Comparison of the T Vs. Wilcoxon Signed-Rank Test for Likert Scale Data and Small Samples. J. Mod. Appl. Stat. Methods 2007, 6, 91-106. [CrossRef]

64. Walsh, J.E. Comments on "the Simplest Signed-Rank Tests". J. Am. Stat. Assoc. 1959, 54, 213-224.

65. Woolson, R.F. Wilcoxon Signed-Rank Test. Wiley Encycl. Clin. Trials 2008. [CrossRef] 